\title{
Aripiprazole Augmentation in Patients with Resistant Obsessive Compulsive Disorder: a Pilot Study
}

\author{
Roberto Delle Chiaie*, Pierluigi Scarciglia, Massimo Pasquini, Maria Caredda and Massimo Biondi
}

Department of Psychiatry and Psychological Medicine, SAPIENZA University of Rome, Viale dell'Università, 30 - 00185 - Rome, Italy

\begin{abstract}
Background: Antipsychotic augmentation is an effective treatment intervention for Obsessive Compulsive Disorder (OCD) patients resistant to Selective Serotonin Reuptake Inhibitors (SSRI) agents. This pilot study was conducted to evaluate the effectiveness and tolerability of Aripiprazole for the augmentation of standard treatments in patients with resistant OCD.

Methods: Twenty patients diagnosed with OCD according to DSM-IV TR criteria and having a history of resistance to standard pharmacological treatment were included in the study. Aripiprazole was added to ongoing SSRI or clomipramine treatment with a starting dose of $5 \mathrm{mg} /$ day and titrated up to a maximum of $20 \mathrm{mg} /$ day (mean dose $12.62 \mathrm{mg} \pm 4.25$ ). Efficacy was assessed with the Yale-Brown obsessive compulsive scale (Y-BOCS) and the Clinical Global Improvementseverity scale (CGI-S) at baseline and at week 12 of Aripiprazole augmentation. Side effects were monitored by the Udvalg for Kliniske Undersogelser (UKU) side effect rating scale.

Results: All 20 subjects enrolled in our study completed the full 12-week course of treatment. A significant improvement over the 12-week study period was observed (paired t-test for mean Y-BOCS total score at week 12 as compared with baseline - all patients: $\mathrm{t}=13.146$, d.f. $=19, \mathrm{p}=0.0001$ ). Aripiprazole was generally well tolerated and no changes were observed in vital signs. The most commonly observed side effects after the introduction of the augmenting agent included: akathysia, nausea/vomiting, hyperkinesia, tension/inner unrest, tremors, asthenia/lassitude/increased fatiguability.

Conclusions: Although results of this pilot study are preliminary and require confirmation in randomized controlled trials, our experience suggested that Aripiprazole is effective and well-tolerated as an augmenting agent in patients with treatment resistant OCD.
\end{abstract}

Keywords: Aripiprazole, augmentation, treatment resistant OCD.

\section{INTRODUCTION}

Obsessive Compulsive Disorder (OCD) is a prevalent and disabling disorder with a lifespan prevalence approximately of $2,5 \%[1,2]$. The disorder follows a fluctuating course and only rarely resolves spontaneously [3].

Most of the patients favourably respond to psychopharmacological interventions with either selective serotonin reuptake inhibitors (SSRIs) or clomipramine. However, while these drugs are consistently superior to placebo, $40 \%$ to $60 \%$ of OCD patients fail to respond to an initial adequate trial and many times a substantial degree of residual symptomathology may persist [4].

There have been many attempts to enhance the effects of SSRIs or clomipramine using several psychotropic compounds as augmenting agents. Conventional antipsychotics have proved effective both in open and in double blind trials $[5,6]$. Atypical antipsychotic have also been tested as add-on agents for treatment resistant OCD patients. Trials have been

\footnotetext{
*Address correspondence to this author at the SAPIENZA University of Rome Viale dell'Università, 30 00185-Roma, Italy; Tel: +390639742364; Fax: +390639038466; E-mail: r.dellechiaie@centrokahlbaum.it
}

succesfully conducted with risperidone [7-10], olanzapine [11-13], amisulpride [14] and quietiapine [15, 16].

Among these new drugs aripiprazole is also considered of interest because of its properties: it is an atypical antipsychotic with partial agonist activity at the dopamine D2 and serotonin 5HT1A receptors and antagonistic activity at the 5HT2-A receptors $[17,18]$.

Clinical efficacy of aripiprazole was observed for the treatment of comorbid obsessive compulsive symptoms in bipolar patients [19], schizophrenics [20] or in children with Tic Disorders [21]. In OCD patients resistant to conventional treatments, aripiprazole's efficacy was first assessed as a monotherapy treatment in an open-label pilot trial [22]. However in these SSRI resistant OCD patients, the drug proved more effective as an augmenting strategy. This was observed in a series of case reports [23-26], and in two small open studies, one conducted on adult patients [27], and another on adolescents [28].

The aim of this study was to provide confirmatory evidence for aripiprazole as a potential augmentation agent in the treatment of a larger sample of refractory OCD adult patients. For this reason we performed an open-label add-on 
study conducted in OCD patients with severe symptoms resistant to standard pharmacological treatments.

\section{MATHERIALS AND METHODS}

\section{Subjects}

The study was carried out at the Outpatient Center of the Department of Psychiatric Science and Psychological Medicine of the SAPIENZA University of Rome during the period February 2007 through October 2009. During this period 28 consecutive patients who had received a diagnosis of OCD according to DSM-IV TR [29] criteria showed to be resistant to standard treatments. Of these 28 patients invited to participate, $20(70 \%)$ were enrolled in the study. The most frequent reason reported by the 8 patients that refused to be enrolled in the study, was their concern for the potential adverse effects of the treatment, due to the off-label use of aripiprazole. The key criterion for inclusion was treatment resistance to SSRIs or clomipramine, defined as no or inadequate response to previous treatment with at least two SSRIs or clomipramine, at an adequate dose and time (at least 12 weeks) [30]. The second inclusion criterion was the severity of the obsessive-compulsive symptomatology as measured on the Y-BOCS [31]. Despite ongoing drug treatment, scores at baseline were of at least 16 or greater. In order to avoid possible methodological drawbacks, all diagnostic procedures were carried out by three senior members of the research team (RDC, MP, MC) with several years of practice and experience in clinical research.

Key criteria for exclusion were the presence of a lifetime history of Bipolar Disorder, Schizophrenia, delirium or other psychotic disorders, personality disorders, a recent history of substance abuse or dependence, suicidal attempts, clinically significant medical disorder, laboratory abnormalities (endocrine, metabolic or ECG) and need for concurrent psychotropic medications other than SSRI $s$, clomipramine or benzodiazepines at bedtime for sleep induction (if necessary).

\section{PROCEDURE AND ASSESSMENT}

Before entering, all subjects gave a written informed consent, according to the procedures approved by the Hospital Committee, following full explanation of the aims of the study, of the off-label use of aripiprazole and of the availability of alternative, proven treatments for OCD.

Treatment outcome was measured by the Y-BOCS total score and the Clinical Global Impressions Severity (CGI-S) [32]. Response was assessed by change in Y-BOCS total score from baseline to endpoint visit and the response criteria were set as follows: "full response" $35 \%$ or greater reduction of Y-BOCS score, "partial response" greater than 25\% but less than 35\% Y-BOCS reduction, "non response" less than $25 \%$ Y-BOCS reduction".

Side effects were monitored with the UKU side effect rating scale [33]. Scales were administred at the end of the first visit (baseline evaluation). Subjects then returned for further follow-up visits, which were set at 3 weeks intervals. At the end of the $4^{\text {th }}$ visit $\left(12^{\text {th }}\right.$ week: endpoint) scales were newly administred. Vital signs and body weight were recorded both at baseline and at endpoint. All raters received specific training in the use of the study instruments.
Unused study medication and the completed medication $\log$ were collected and reviewed at each visit to assess treatment compliance.

Aripiprazole, was administered in the morning and was added to ongoing SSRI or clomipramine with a starting dose of $5 \mathrm{mg} / \mathrm{day}$ in the morning. This dose was titrated up to a maximum of $20 \mathrm{mg} / \mathrm{day}$, according to the patients clinical response and tolerability. Maximum dose reached was 20 $\mathrm{mg}$ /day (mean dose 12,62 $\mathrm{mg} \pm 4,25$ ).

\section{Statistical Analysis}

We used a descriptive analysis to study the frequency distribution of all variables of interest, and the paired t-test to examine differences in scores on outcome measures at baseline and follow-up assessments. SPSS for Windows, version 13.0 was used for all analyses.

\section{RESULTS}

All of 20 subjects enrolled in our study completed the full 12-weeks course of treatment. The sample was composed of 13 men and 7 female patients, all Caucasian and all yet treated for their OCD with a conventional therapy. Their ages ranged from 24 to 49 years (mean age $32,40 \pm 6,38$ ) with a mean duration of disorder of 12,5 years $( \pm 6,72)$. All patients were on a standard anti OCD therapy: 14 patients were on clomipramine (mean dose 153,57 $\mathrm{mg} \pm 33,40$ ), 5 patients were on paroxetine (mean dose $52 \mathrm{mg} \pm 8,36$ ) and 1 patient was on fluvoxamine (daily dose $300 \mathrm{mg}$ ). Sociodemographic and clinical characteristics of the twenty patients are shown in Table $\mathbf{1}$.

Overall, a significant improvement in OCD symptoms was observed (Tables 2-3). On the basis of the Y-BOCS scores reduction response criterion, after the aripiprazole add-on $16(80 \%)$ patients showed full response, $2(10 \%)$ patients showed partial response and $2(10 \%)$ patients were non responders. A significant reduction from baseline to endpoint was also showed by CGI-S scores.

Aripiprazole was generally well tolerated and no changes were observed in vital signs. Baseline UKU scale scores were significantly reduced at endpoint (BL: $8,25 \pm 4,96$, EP: $6.25 \pm 4,65 ; \mathrm{p}<.001)$.

The most commonly observed side effects after the introduction of the augmenting agent included akathysia (25\%), nausea/vomiting (15\%), hyperkinesia (15\%), Tension/Inner unrest $(10 \%)$, tremors and asthenia/lassitude/increased fatiguability (10\%). These symptoms never reached a score of 3 on the UKU scale. Among other adverse effects, mainly observed in patients under clomipramine, were dry mouth (35\%), constipation (35\%), erectile and ejaculative dysfunctions $(20 \%)$. None of these required drug discontinuation.

\section{DISCUSSION}

In this open-label study was considered a larger sample than previous studies conducted till now. Our results confirm that aripiprazole augmentation may be effective and well tolerated in patients with OCD refractory to standard treatments. 
Table 1. Sociodemographic and Clinical Characteristics

\begin{tabular}{|c|c|c|c|c|c|c|}
\hline Patient & Sex & Age & Duration of OCD & AD Drug & $\begin{array}{l}\text { AD Dose } \\
\text { (mg/day) }\end{array}$ & Aripiprazole (mg/day) \\
\hline 1 & $\mathrm{~F}$ & 41 & 5 & Clomipramine & 150 & 10 \\
\hline 3 & M & 37 & 15 & Clomipramine & 150 & 20 \\
\hline 4 & M & 39 & 19 & Clomipramine & 225 & 15 \\
\hline 6 & M & 30 & 14 & Paroxetine & 50 & 10 \\
\hline 7 & M & 27 & 6 & Paroxetine & 50 & 10 \\
\hline 8 & M & 31 & 10 & Clomipramine & 150 & 15 \\
\hline 9 & $\mathrm{~F}$ & 30 & 10 & Clomipramine & 112,5 & 10 \\
\hline 13 & M & 38 & 25 & Clomipramine & 150 & 20 \\
\hline 14 & $\mathrm{~F}$ & 26 & 3 & Fluvoxamine & 300 & 10 \\
\hline 15 & M & 49 & 22 & Clomipramine & 150 & 10 \\
\hline 16 & $\mathrm{~F}$ & 32 & 13 & Clomipramine & 125 & 10 \\
\hline 17 & M & 37 & 24 & Clomipramine & 150 & 7,5 \\
\hline 18 & M & 27 & 8 & Clomipramine & 150 & 15 \\
\hline 19 & M & 24 & 6 & Paroxetine & 60 & 15 \\
\hline 20 & $\mathrm{~F}$ & 29 & 10 & Clomipramine & 225 & 15 \\
\hline
\end{tabular}

A full response was observed in $80 \%$ of the 20 patients treated in this study. Such rate of responders is higher than the rates observed by Connor [22] and Pessina [27]. Some methodological differences might account for this discrepancy. With respect to the Connor study, since it was an aripiprazole monotherapy trial, higher response rates obtained in our add-on study could depend upon this difference. In the Pessina study, only 8 out 12 of the enrolled patients completed the 12 weeks trial, while all of our 20 subjects were completers. These differences could have influenced the higher rate of responders found in our study.

However, even if some of these differences could partially explain our better results, our data are interesting, because we set the response threshold at a level of 35\% reduction of the Y-BOCS score from baseline to endpoint to define a "full response", while in the previous two studies this level was set at $30 \%$ and at $25 \%$ respectively. We cannot rule out anyhow the possibility that our pattern of findings may differ from previous studies depending on different OCD subtypes observed.

High response rates however, have been reported also in several other studies when other antipsychotics were added as augmenting agents to standard treatments in patients with refractory OCD, such as 65\% for haloperidol [5], 50\%$71.4 \%$ for quetiapine $[15,16], 50 \%-85 \%$ for risperidone $[9,10]$ and $43.5 \%-70 \%$ for olanzapine $[12,13]$. The highest response rate among these augmentation trials was observed in the amisulpride study (90\%)[14]. Although the study de- signs, definitions of resistance and response criteria were different, an explanation for the high rate of response to aripiprazole augmentation might lie in its pharmacodynamic profile.

The role of the serotonergic system in the aetiology of OCD is well known, but not sufficiently to understand the disorder thoroughly. Indeed, a range of other neurochemical systems may be implicated in OCD, and the dopamine system has been a particular focus of attention [34]. On the other hand, the increased dopaminergic activity may play a role in the pathophysiology of OCD and seems to point out that, among the properties of antipsychotic drugs, dopamine antagonism may contribute to enhance the efficacy of SSRIs in treatment resistant OCD patients.

According to Positron Emission Tomography studies, atypical antipsychotics cause high levels of 5HT2 antagonism at low doses, whereas relatively high doses are required to produce significant dopamine D2 antagonism [35].

In all the studies in which atypical antipsychotics were found to be effective augmenting agents for treatment resistant OCD patients, significant results were reported at lower doses than those currently recommended for treatment of psychotic disorders [36]. This may indicate that the augmentation of the ongoing anti OCD treatment obtained when these compounds are added, is mainly based on a modulation of the serotonin transmission rather than on a functional antagonism on the dopamine system. Moreover, since low 
Table 2. Outcome Measures

\begin{tabular}{|c|c|c|c|c|c|c|c|}
\hline Patient & $\begin{array}{c}\text { BL } \\
\text { Y-BOCS }\end{array}$ & $\underset{\text { Y-BOCS }}{\text { EP }}$ & Response & BL CGI-S & EP CGI-S & BL UKU Scale & EP UKU Scale \\
\hline 1 & 26 & 12 & Full response & 4 & 2 & 7 & 3 \\
\hline 3 & 24 & 9 & Full response & 5 & 2 & 8 & 5 \\
\hline 4 & 30 & 16 & Full response & 6 & 3 & 14 & 10 \\
\hline 6 & 23 & 14 & Full response & 4 & 2 & 4 & 2 \\
\hline 7 & 28 & 10 & Full response & 5 & 3 & 0 & 2 \\
\hline 8 & 30 & 18 & Full response & 6 & 2 & 9 & 4 \\
\hline 9 & 24 & 10 & Full response & 4 & 2 & 5 & 2 \\
\hline 13 & 34 & 18 & Full response & 6 & 2 & 11 & 7 \\
\hline 14 & 32 & 12 & Full response & 5 & 3 & 5 & 3 \\
\hline 15 & 26 & 18 & Partial response & 4 & 3 & 10 & 4 \\
\hline 16 & 28 & 22 & Non Response & 5 & 2 & 8 & 5 \\
\hline 17 & 38 & 32 & Non Response & 6 & 5 & 15 & 18 \\
\hline 18 & 31 & 10 & Full response & 6 & 3 & 18 & 15 \\
\hline 19 & 28 & 10 & Full response & 5 & 3 & 8 & 10 \\
\hline 20 & 32 & 18 & Full response & 5 & 3 & 15 & 12 \\
\hline
\end{tabular}

CGI-S: Clinical Global Impression-Severity Scale; Y-BOCS: Yale-Brown Obsessive

Compulsive Scale; BL: Baseline, EP: Endpoint.

Table 3. Outcome Measures

\begin{tabular}{|c|c|c|c|c|}
\hline Y-BOCS BL & Y-BOCS EP & $t$ & $d f$ & $p$ \\
\hline $5,1( \pm 0,71)$ & $2,55( \pm 0,75)$ & 12,856 & 19 & .0001 \\
\hline
\end{tabular}

Note. Paired t-tests are used for differences of means. $\mathrm{P}=$ by the two-tailed

$t$-test. CGI-S: Clinical Global Impression-Severity Scale; Y-BOCS: Yale-Brown Obsessive

Compulsive Scale; BL: Baseline, EP: Endpoint.

doses of antipsychotics mainly antagonize dopamine presynaptic autoreceptor, this mechanism is more likely to increase or modulate, rather than antagonize dopaminergic transmission.

Furthermore, the high response rates we observed could depend on other pharmacologic properties of aripiprazole, such as its partial agonism at 5HT1a receptors. In fact the increase in synaptic 5HT caused by SSRIs activates feedback mechanisms mediated by 5HT-1a (cell body) and 5HT1b (terminal) autoreceptors, wich, respectively, reduce the firing in 5HT neurons and decrease the amount of 5HT released per action potential, resulting in attenuated 5HT neurotransmission [37]. Partial agonism of aripiprazole at serotonin 5HT-1 autoreceptors could modulate or reduce this mechanism, resulting in an enhanced anti OCD efficacy of SSRIs.
For these reasons, the unique pharmacological profile of aripiprazole based on its partial agonistic properties on dopamine transmission, could bring an advantage over other atypical antipsychotics in the treatment of refractory OCD and partially explain the results of our study.

The present study has some limitations First, the lack of a placebo-controlled group which might mean that the results may reflect a natural improvement in OCD or a placebo effect. Second, the use of different antidepressants for standard treatment. Third, the small sample size and the open design of the study. As such the results are preliminary and require confirmation in a randomized controlled trial.

To conclude, this study suggests that, as an augmenting agent, aripiprazole is effective and well tolerated in patients with treatment resistant OCD. 


\section{REFERENCES}

[1] Karno M, Golding JM, Sorenson SB, Burnam MA. The epidemiology of obsessive compulsive disorder in five US communities. Arch Gen Psychiatry 1988; 45: 1094-9.

[2] Sasson Y, Zohar J, Chopra M, et al. Epidemiology of obsessive compulsive disorder: a world view. J Clin Psychiatry 1997; 58 (suppl 12): 7-10.

[3] Rasmussen SA, Eisen JL. Treatment strategies for chronic and refractory obsessive-compulsive disorder. J Clin Psychiatry 1997; 58 (suppl 13): 9-13.

[4] Hollander E, Bienstock CA, Koran ML, Pallanti S, Marazziti D, Rasmussen SA, Ravizza L, Benkelfat C, Saxena S, Greenberg BD, Sasson Y, Zohar J. Refractory obsessive compulsive disorder: state-of-the-art treatment. J Clin Psychiatry 2002; 63 (suppl 6): 209.

[5] McDougle CJ, Goodman WK, Leckman JF, et al. Haloperidol addition in fluvoxamine-refractory obsessive-compulsive disorder. A double blind, placebo controlled study in patients with and without tics. Arch Gen Psychiatry 1994; 51: 302-8.

[6] Sareen J, Kirshner A, Lander M, Kjernisted KD, Eleff MK, Reiss JP. Do antipsychotics ameliorate or exacerbate obsessive compulsive disorder symptoms? A systematic review. J Affect Disorders 2004; 82: 167-74.

[7] Saxena S, Wang D, Bystritski A, Baxter LR Jr. Risperidone augmentation of SRI treatment for refractory obsessive convulsive disorder. J Clin Psychiatry 1996; 57: 303-6.

[8] Pfanner C, Marazziti D, Dell'Osso L. Risperidone augmentation in refractory obsessive compulsive disorder: an open label study. Int Clin Psychopharmacol 2000; 15: 297-301.

[9] McDougle CJ, Epperson CN, Pelton GH, Wasylink S, Price LH. A double blind placebo controlled study of risperidone addition in serotonin reuptake inhibitor-refractory obsessive compulsive disorder. Arch Gen Psychiatry 2000; 57: 794-801.

[10] Jacobsen FM. Risperidone in the treatment of affective illness and obsessive compulsive disorder. J Clin Psychiatry 1995 ; 56: 423-9.

[11] Koran LM, Ringold AL, Elliott MA. Olanzapine augmentation for treatment resistant obsessive compulsive disorder. J Clin Psychiatry 2000; 61: 514-7.

[12] Bogetto F, Bellino S, Vaschetto P, Ziero S. Olanzapine augmentation of fluvoxamine refractory obsessive compulsive disorder (OCD): a 12 week open trial. Psychiatry Res 2000; 96: 91-8.

[13] Francobandiera G. Olanzapine augmentation of serotonin uptake inhibitors in obsessive compulsive disorder: an open study. Can J Psychiatry 2001; 46: 356-8.

[14] Metin O, Yazici K, Tot S, Yazici AE. Amisulpiride augmentation in treatment resistant obsessive compulsive disorder: an open trial. Human Psychopharmacol 2003; 18: 463-7.

[15] Mohr N, Vythilingum B, Emsley RA, Stein DJ. Quetiapine augmentation of serotonin reuptake inhibitors in obsessive compulsive disorder. Int Clin Psychopharmacol 2002 ; 17: 37-40.

[16] Atmaca M, Kuloglu M, Tezcan E, Gecici O. Quetiapine augmentation in patients with treatment resistant obsessive compulsive disorder. Int Clin Psychopharmacol 2002; 17: 115-9.

[17] Jordan S, Koprivica V, Chen R. The antipsychotic aripiprazole is a potent, partial agonist at the human 5HT1a receptor. Eur J Pharmacol 2002; 441: 137-40.

[18] Lieberman JA. Dopamine partial agonists:a new class of antipsychotics. CNS Drugs 2004; 18: 251-67.

[19] Uguz F. Successful treatment of comorbid obsessive-compulsive disorder with aripiprazole in three patients with bipolar disorder. Gen Hosp Psychiatry 2010, 32: 556-8.
[20] Glick ID, Poyurovsky M, Iranova O, Koran LM. Aripiprazolein schizophrenia patients with comorbid obsessive-compulsive symptoms: an open-label study of 15 patients. J Clin Psychiatry 2008, 69: $1856-9$.

[21] Murphy TK, Mutch PJ, Reid JM, Edge PJ, Storch EA, Bengstone M, Yang M. Open label Aripiprazole in the treatment of youth with Tic Disorder. J Child and Adolescent Psychopharmacol 2009, 19: 441-7.

[22] Connor KM, Payne VM, Gadde KM, Zhang W, Davidson JRT The use of aripiprazole in obsessive compulsive disorder: preliminary observations in 8 patients. J Clin Psychiatry 2005; 66: 49-51.

[23] Da Rocha FF, Correa H. Successful augmentation with aripiprazole in clomipramine-refractory obsessive-compulsive disorder. Prog Neuropsychopharmacol Biol Psychiatry 2007; 31: 1550-1.

[24] Sarkar R, Klein J, Kruger S. Aripiprazole augmentation in treatment refractory obsessive-compulsive disorder. Psychopharmacology 2008 ; 197: 687-8.

[25] Fornaro M, Gabrielli F, Mattei C, Vinciguerra V, Fornaro P. Aripiprazole augmentation in poor insight obsessive-compulsive disorder: a case report. Annals of General Psychiatry 2008; 7: 26.

[26] Storch EA, Lehmkuhl H, Geffken GR, Touchton A, Murphy TK. Aripiprazole augmentation of incomplete treatment response in an adolescent male with obsessive-compulsive disorder. Depress Anxiety 2008; 25: 172-4.

[27] Pessina E, Albert U, Bogetto F, Maina G. Aripiprazole augmentation of serotonin reuptake inhibitors in treatment-resistant obsessive-compulsive disorder: a 12-week open-label preliminary study. Inter Clin Psychopharmacol 2009; 24: 265-9.

[28] Masi G, Pfanner C, Millepiedi S, Berloffa S. Aripiprazole augmentation in 39 adolescents with medication-resistant obsessivecompulsive disorder. J Clin Psychopharmacol 2010; 30: 688-93.

[29] American Psychiatric Association. Diagnostic and Statistical manual of Mental Disorders, $4^{\text {th }}$ Ed. Text revision. Washington DC: American Psychiatric Association 2000.

[30] Iancu I, Dannon PN, Dolberg OT, Zohar J. Treatment of obsessive compulsive disorder: from theory to practice. In: Halbreich U, Montgomery SA, ed. Pharmachotherapy for Mood, Anxiety and Cognitive Disorders. Washington DC: American Psychiatric Press 2000; p 465-78.

[31] Goldman WK, Price LH, Rasmussen SA. The Yale-Brown obsessive compulsive scale. I. Development, use and reliability. Arch Gen Psychiatry 1989; 46: 1006-11.

[32] National Institute of Mental Health. Clinical Global Impressions (CGI) scale. Psychopharmacol Bull 1985; 21: 839-43.

[33] Lingjaerde O, Ahlfors UG, Bech P, Dencker SJ, Elgen K. The UKU side effect rating scale. A new comprehensive rating scale for psychotropic drugs and a cross sectional study of side effects in neuroleptic treated patients. Acta Psychiatry Scand 1987; 76 (334, suppl): $1-10$.

[34] Stein DJ. Obsessive-compulsive Disorder. The Lancet 2002; 360 397-405.

[35] Kapur S, Zipursky RB, Remington G, Jones C, DaSilva J, Wilson AA, Houle S. 5HT2 and D2 receptor occupancy of olanzapine in schizophrenia. A PET investigation. Am J Psychiatry 1998; 155: 921-8.

[36] Conley RR, Kelly DL. Manegement of treatment resistance in schizophrenia. Biol Psychiatry 2001; 50: 898-911.

[37] Blier P. Possible neurobiological mechanism underlying faster onset of antidepressant action. J Clin Psychiatry 2001; 62 (suppl 4): $7-11$

(C) Delle Chiaie et al.; Licensee Bentham Open.

This is an open access article licensed under the terms of the Creative Commons Attribution Non-Commercial License (http://creativecommons.org/licenses/by-nc/3.0/) which permits unrestricted, non-commercial use, distribution and reproduction in any medium, provided the work is properly cited. 